\title{
Molecular Alterations of Barrett's Esophagus on Microdissected Endoscopic Biopsies
}

\author{
Solange Romagnoli, Massimo Roncalli, Daniela Graziani, Barbara Cassani, \\ Elena Roz, Luigi Bonavina, Alberto Peracchia, Silvano Bosari, and Guido Coggi
}

Il Department of Pathology (SR, SB, GC, DG, BC, ER), University of Milan School of Medicine; San Paolo Hospital (SR, SB, GC); IRCCS Ospedale Maggiore (SR, SB, GC, LB, AP); Department of Pathology (MR), University of Milan School of Medicine at Humanitas Clinical Institute; Department of Clinical Surgery (LB, AP), University of Milan School of Medicine; and Centro Interuniversitario di Ricerche Oncologiche (GC), Milan, Italy

SUMMARY: Alterations in proto-oncogenes and tumor suppressor genes play a role in the sequence from Barrett's metaplasia to esophageal adenocarcinoma. The present study aims to ascertain whether molecular abnormalities take place in Barrett's metaplasia and low-grade dysplasia and to correlate them with the histological features of the esophageal mucosa. Forty-one formalin-fixed, paraffin-embedded endoscopic esophageal biopsies were classified according to the type of metaplastic changes (noncolumnar fundic and cardial metaplasia; columnar metaplasia, with and without intestinal features). After microdissection samples were examined for loss of heterozygosity ( $\mathrm{LOH}$ ) using polymorphic markers on $5 \mathrm{q}$ (D5S82), corresponding to $A P C$ (adenomatous polyposis coli) gene, 13q (CA repeat in intron 2 position 14815 to 14998 of the retinoblastoma gene), 17p (D17S513) corresponding to p53 locus, and for p53 mutations. Molecular alterations including LOH, allelic imbalance, and microsatellite instability could be detected in all types of metaplastic changes and sporadically in the squamous epithelium adjacent to the metaplastic tissue. Molecular alterations involving microsatellites D5S82 and the CA repeat inside the retinoblastoma gene were more frequent in nonintestinal metaplasia whereas those involving the p53 locus took place in columnar intestinal metaplasia and in low-grade dysplasia. Clonal changes were demonstrated in different metaplastic areas in three patients. Genetic alterations comprising LOH and microsatellite instability characterize Barrett's mucosa and appear related to the type of metaplastic change. Some of them precede the development of intestinal metaplasia, suggesting that genetic alterations take place earlier than previously thought. (Lab Invest 2001, 81:241-247).

$B$ arrett's esophagus, caused by the chronic injury of the gastric acid reflux, is a precancerous condition. It is estimated that the risk of neoplasia in Barrett's esophagus, through the intermediate step of dysplastic transformation of the columnar epithelium, is 125 -fold higher than in general population (Souza and Meltzer, 1997). A number of molecular abnormalities under the form of proto-oncogene alterations, loss of heterozygosity ( $\mathrm{LOH}$ ) of putative tumor suppressor genes, mutations of tumor suppressor genes, and microsatellite instability are thought to represent the genetic background of metaplastic and dysplastic changes. Allelic losses at multiple chromosomal loci corresponding to diverse tumor suppressor genes have been demonstrated in esophageal adenocarcinoma (Barrett et al, 1996; Hammoud et al, 1996; Huang et al, 1992; Meltzer, 1996; Ying et al, 1992). In particular 17p LOH, corresponding to p53 locus, has been implicated in most adenocarcinomas at a rate

Received November 22, 2000.

This work has been supported in part by grants from Ministero dell'Università e della Ricerca Scientifica e Tecnologica (M.U.R.S.T.) and Cassa di Risparmio delle Provincie Lombarde (CARIPLO).

Address reprint requests to: Dr. Solange Romagnoli, II Department of Pathology, University of Milan School of Medicine, Via A di Rudinì 8, 20142 Milano, Italy.E-mail: solange.romagnoli@unimi.it ranging from $50 \%$ to $90 \%$ (Blount et al, 1994; Meltzer et al, 1991; Montesano et al, 1996). Other loci and corresponding tumor suppressor genes such as $5 \mathrm{q}$, the adenomatous polyposis coli (APC) locus, 13q, the retinoblastoma $(R b)$ locus, and $18 \mathrm{q}$, the deleted in colon cancer (DCC) locus, have been proposed to have a causative role in esophageal adenocarcinogenesis ( Blount et al, 1993; Boynton et al, 1991; Gonzalez et al, 1997; Zhuang et al, 1996).

Investigators have also attempted to delineate a specific molecular sequence of genetic damage, showing that $17 \mathrm{p} \mathrm{LOH}$ represents an early event that usually precedes $5 q$ and $18 q \mathrm{LOH}$ during the progression from Barrett's esophagus to dysplasia and then to adenocarcinoma. Among the tumor suppressor genes, p53 inactivation by mutation remains the most investigated both by immunohistochemistry and molecular biology. In particular, p53 has been found mutated not only in esophageal adenocarcinoma but also in Barrett's esophagus with and without dysplasia (Casson et al, 1991; Gleeson et al, 1995; Hamelin et al, 1994; Neshat et al, 1994; Schneider et al, 1996). Microsatellite instability takes place at highly repeated sequences corresponding to microsatellite polymorphic loci. It is considered a sign of DNA replication infidelity caused by mutations in DNA mismatch repair genes (MRG) like MSH 2 on chromosome $2 \mathrm{p}$ and $M L H$ 
1 on chromosome 3p. Microsatellite instability has been demonstrated both in Barrett's metaplasia and esophageal adenocarcinoma (Meltzer et al, 1994).

Although several studies have investigated the role of different oncogenes and tumor suppressor genes in esophageal carcinogenesis (Dolan et al, 1999; Jankowski et al, 1999; Roncalli et al, 1998; Walch et al, 2000; Wu et al, 1998), focusing on the advanced stages of progression from dysplasia to neoplasia, scarce data are available on genetic alterations occurring in Barrett's esophagus in the absence of neoplastic and/or dysplastic changes (Campomenosi et al, 1996; Galipeau et al, 1999 ). Three major histological forms of Barrett's esophagus have been described: a specialized columnar type, a cardiac type, and a fundic type. The most distinctive is the specialized columnar type, which is a mixture of gastric and intestinal mucous cells. The other forms of Barrett's epithelium resemble cardiac and atrophic fundic mucosa, respectively. Only columnar metaplasia is indicative of Barrett's esophagus, whereas the other two types require correlation with the exact location of the biopsy site (Goldman et al, 1996).

Molecular alterations of the different types of metaplastic mucosa have not been investigated. We microdissected various types of mucosal metaplasia from endoscopic biopsies of Barrett's esophagus unassociated with esophageal adenocarcinoma and evaluated molecular alterations of markers on $5 q$ (D5S82), 17p (D17S513), 13q (CA repeat intron 2 of retinoblastoma, position 14815 to 14998$)$, as well as p53 gene mutations. The aim of our investigation was to assess the early molecular alterations characterizing Barrett's esophagus.

\section{Results}

Microdissection of the 41 specimens yielded 118 samples available for the study. The distribution of microdissected samples according to the different types of metaplasia and dysplasia was the following: 26 normal tissue samples, 38 squamous tissue, 12 cardial metaplasia, 13 atrophic fundic metaplasia, 4 columnar metaplasia, 12 columnar and intestinal metaplasia, 3 columnar metaplasia and low-grade dysplasia, 10 columnar and intestinal metaplasia and low-grade dysplasia (Fig. 1).

\section{p53 Mutation}

p53 mutations were detected in 10 of 102 (9.8\%) samples microdissected from 10 specimens (24\%). The details of $p 53$ mutations in the microdissected samples are reported in Table 1. Overall, p53 mutations were detected in $8 \%$ of cases without columnar metaplasia compared with $20 \%$ with intestinal columnar metaplasia and $30 \%$ with low-grade dysplasia.

p53 mutations were also detected in morphologically normal squamous tissue (6\% of cases) adjacent to metaplastic lesions. p53 mutations were confirmed by DNA sequencing in six cases with the following results: mutation at the splicing site between intron 4/exon 5 (TGCAG to TACAG) in two cases corresponding to a squamous tissue and a sample of intestinal metaplasia with low-grade dysplasia; a mutation at codon 243, exon 7, from ATG to ACG, with methionine to threonine substitution, in a columnar metaplasia with low-grade dysplasia; a mutation at codon 261, exon 7, AGT to AAT, with serine to asparagine substitution, in one case of intestinal metaplasia; a mutation at codon 225, exon 7, GTT to GCT, with valine to alanine substitution, in squamous tissue; mutation of codon 307, exon 8, GCA to ACA, with alanine to threonine substitution, in intestinal metaplasia. In all other cases, we could not confirm the results obtained by single-strand conformation polymorphism (SSCP) because of the scarcity of DNA template obtained by microdissection.

\section{7p, 13q, $5 q \mathrm{LOH}$}

Of the total samples, $73 \%, 90 \%$, and $64 \%$ provided informative results for $17 p, 13 q$, and $5 q$, respectively. Squamous epithelium showed four molecular alterations at the D17S513 marker characterized by two $\mathrm{LOH}$ (2 samples) and one microsatellite instability; a further alteration was observed as allelic imbalance at the D5S82 locus.

In nonintestinal metaplasia, D5S82, D17S513, and $R b$ CA repeat molecular alterations comprised $25 \%$, $25 \%, 20 \%$ of cases, respectively, whereas in intestinal metaplasia they ranged from 0\% (D5S82) to 25\% (D17S513), as shown in detail in Table 2. Molecular alterations-either losses, imbalances, or instabilities-tend to occur more frequently in nondysplastic
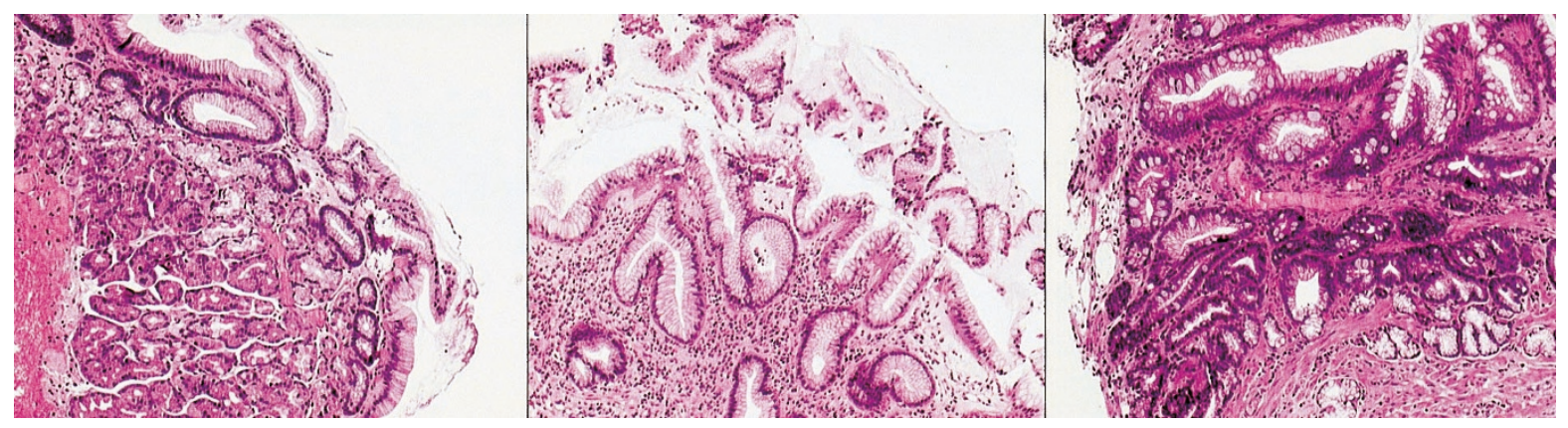

\section{Figure 1.}

Hematoxylin-eosin sections of esophageal biopsies showing different types of Barrett's epithelium. From left to right: fundic atrophic type, cardial type, and intestinal type (magnification: $\times 20, \times 40, \times 40)$ 
Table 1. Distribution of p53 Mutations, Exons 5 to 8, Performed on 102 Microdissected Samples

\begin{tabular}{lcccccc}
\hline $\begin{array}{c}\text { Type of microdissected } \\
\text { sample }\end{array}$ & $\begin{array}{c}\text { Mutations per } \\
\text { sample type }\end{array}$ & $\%$ & Exon 5 & Exon 6 & Exon 7 & Exon 8 \\
\hline Normal tissue & $0 / 26$ & 0 & - & - & - & - \\
Squamous tissue & $2 / 30$ & 7 & 1 & - & 1 & - \\
Cardial metaplasia & $1 / 12$ & 8 & - & - & 1 & - \\
Fundic metaplasia & $1 / 8$ & 13 & - & 1 & - & - \\
Columnar metaplasia & $0 / 3$ & 0 & - & - & - & - \\
Intestinal metaplasia & $2 / 10$ & 20 & - & - & 1 & - \\
Columnar metaplasia + & $2 / 3$ & 67 & - & - & 2 & - \\
$\quad$ low-grade dysplasia & & & & & 1 & - \\
Intestinal metaplasia + & $2 / 10$ & 20 & 1 & - & & \\
low-grade dysplasia & & & & &
\end{tabular}

cases, either with or without intestinal metaplasia, as shown in Table 2. In two patients microsatellite instability observed respectively for two (CA repeat intron 2 of $R b, \mathrm{D} 5 \mathrm{~S} 82)$ and three markers suggests, at least in the latter case, a replicating error (RER) phenotype (Fig. 2C).

\section{Clonal Changes in Samples from the Same Patient}

In three patients the same molecular alteration was documented in two or more microdissected samples. In the first case, allelic instability for D17S513 was detected in both squamous epithelium and in lowgrade dysplasia associated with intestinal metaplasia.

In the second patient, we documented a p53 exon 7 mutation in both squamous tissue and cardial metaplastic tissue; in addition, allelic imbalance for D5S82 was present in squamous tissue and $\mathrm{LOH}$ in cardial metaplasia (Fig. 2A). In the third patient, $\mathrm{LOH}$ for D17S513 was demonstrated in both squamous tissue and atrophic fundic metaplasia (Fig. 2B). Therefore, in all these cases, alterations involved either the D17S513 locus or the p53 gene.

\section{Discussion}

The present study aims to assess the molecular alterations in bioptic material of patients bearing Barrett's esophagus and to ascertain by means of a new tool, like the microdissection technique, the molecular background of each different type of Barrett's metaplasia and even of normal squamous tissue adjacent to metaplastic tissue. Several studies have demon- strated molecular alterations in nondysplastic Barrett's mucosa as well as in low- and high-grade dysplasia in cases of adenocarcinoma arising from Barrett's mucosa. Because most of these studies have been carried out on resected specimens harboring esophageal adenocarcinoma, widespread mutational events involving the adjacent nonneoplastic mucosa, so called 'field cancerization,' might have biased the aforementioned results. Few data have been published correlating the molecular genotype and the different metaplastic changes of Barrett's mucosa, especially in nondysplastic or low-grade dysplastic lesions (Campomenosi et al, 1996).

We used a relatively new approach and microdissected endoscopic biopsies obtained in patients with Barrett's esophagus to obtain samples specific for every type of metaplastic tissue. This technique ensures enrichment and purity of the tissues to be studied and guarantees the specificity of the molecular events encountered.

In contrast to the abundant data implicating p53 mutations (occurring in up to $60 \%$ of cases) in esophageal adenocarcinoma and immediate precursors such as high-grade dysplasia (Hamelin et al, 1994; Neshat et al, 1994; Schneider et al, 1996), data on the molecular genetics of the metaplastic mucosa harboring low-grade or no dysplasia are relatively scarce. These studies suggest that the role of p53 mutations in these earlier lesions is less strong than in advanced ones. Nevertheless, these data lack accuracy in exactly defining the grade of dysplasia and are also limited by the small number of cases investigated.

Table 2. Molecular Changes in Nondysplastic and Low-Grade Dysplastic Barrett's Esophagus Showing the Type, Frequency, and Percentage of Microsatellite Molecular Alterations According to Metaplastic Tissue Type

\begin{tabular}{lccc}
\hline & \multicolumn{3}{c}{ Number and type of alteration/number of samples (\%) } \\
\cline { 2 - 4 } & D5S82 & Rb CA repeat & D17S513 \\
\hline Squamous epithelium & $1 \mathrm{Al} / 23(4 \%)$ & $0 / 33(0 \%)$ & $2 \mathrm{LOH}, 1 \mathrm{MIS} / 26(11 \%)$ \\
Nonintestinal metaplasia & $2 \mathrm{LOH}, 2 \mathrm{MIS} / 16(25 \%)$ & $1 \mathrm{Al}, 2 \mathrm{LOH}, 3 \mathrm{MIS} / 24(25 \%)$ & $2 \mathrm{LOH}, 1 \mathrm{MIS} / 15(20 \%)$ \\
Intestinal metaplasia & $0 / 8(0 \%)$ & $1 \mathrm{Al}, 1 \mathrm{MIS} / 11(18 \%)$ & $1 \mathrm{LOH} / 4(25 \%)$ \\
Low-grade dysplasia & $0 / 6(0 \%)$ & $0 / 12(0 \%)$ & $1 \mathrm{MIS} / 10(10 \%)$ \\
\hline
\end{tabular}

Al, allelic imbalance; LOH, loss of heterozygosity; MIS, microsatellite instability.

* Including cases with multiple microsatellite instabilities. 

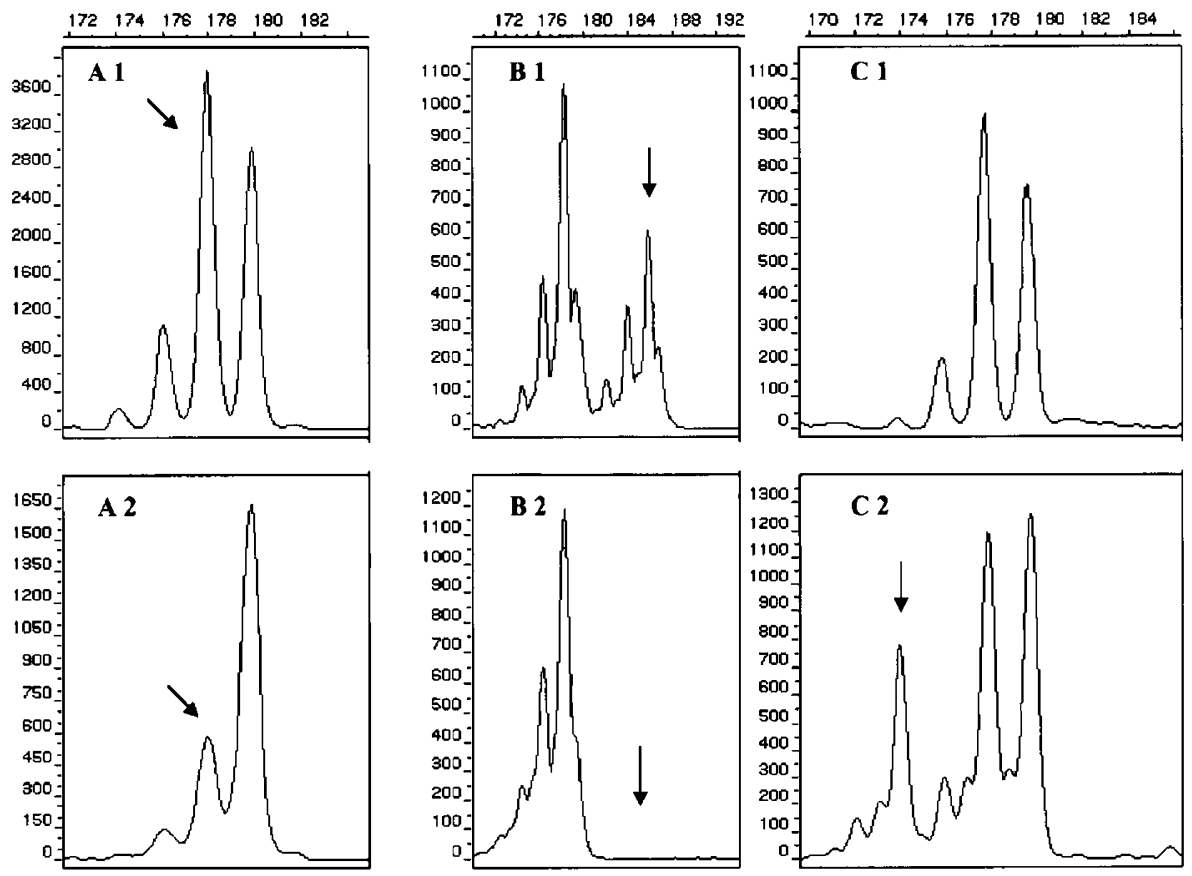

Figure 2.

A, Allelic loss (LOH) of D5S82 in cardial metaplasia (A2) compared with normal tissue (A1). B, Allelic loss (LOH) of D17S513 in squamous tissue (B2) compared with normal tissue (B1). C, D5S82 microsatellite instability in columnar metaplasia compared with normal tissue. The arrows show the allele lost (A2, B2) or unstable (C2).

The pattern of $\mathrm{LOH}$ among the most studied regions, corresponding to the tumor-suppressor genes APC (5q), Rb (13p), and p53 (17p), appears more heterogeneous. Loss of heterozygosity, allelic instability, and allelic imbalance have been detected much earlier than the mutational events that are a feature of severe dysplastic and neoplastic changes.

In our cases, p53 mutations are present throughout the whole spectrum of metaplastic changes and, interestingly, even in the histologically normal squamous epithelium. The rate of $p 53$ mutations increases from squamous epithelium to columnar metaplasia with low-grade dysplasia. In particular, p53 mutations become a more common feature of the subset of samples showing columnar metaplasia associated with intestinal differentiation (20\%) or low-grade dysplasia (30\%).

Thus, the pattern of $p 53$ mutations in the different microdissected tissue samples suggests that the mutational inactivation of this tumor suppressor gene may occur within a molecularly damaged squamous epithelium that is devoid of morphologic changes. The squamous mucosa progresses directly, or through intermediate steps such as cardial and atrophic metaplasia, to columnar metaplasia, with or without intestinal differentiation, and then to low-grade dysplasia. Genetic abnormalities in these early lesions are more frequently a feature of columnar metaplasia than of intestinal metaplasia, which is today considered a tissue marker for patients at risk of cancer with Barrett's mucosa. Similarly, D17S513 allelic losses are detected in a small number of samples with squamous epithelium and cardial metaplasia, whereas the prev- alence increases in columnar epithelium with intestinal metaplasia.

Although both $A P C$ and $R b$ gene abnormalities have been detected in Barrett's adenocarcinoma, in $80 \%$ and $50 \%$ cases, respectively (Barrett et al, 1996; Boynton et al, 1991; Zhuang et al, 1996), very little is known on the involvement of these genes in earlier steps of esophageal tumorigenesis. Analysis of lowand high-grade lesions associated with adenocarcinoma showed 14\% 17p LOH in Barrett's adenocarcinoma and $42 \%$ in low-grade dysplasia and $10 \% 5 q$ $\mathrm{LOH}$ in Barrett's and $21 \%$ in low-grade lesions with a clonal origin of such molecular alterations (Wu et al, 1998). Our cases show that molecular alterations of $R b$ CA repeat are detectable in all types of Barrett's metaplasia, ranging from $18 \%$ of intestinal metaplasia up to $30 \%$ in atrophic fundic metaplasia. Molecular alterations involving D5S82, which were mainly represented in cardial metaplasia (33\% of samples), showed a similar incidence. D5S82 LOH were present in a much smaller number of cases harboring atrophic fundic metaplasia (12\%) and columnar epithelium with and without intestinal metaplasia (10\%). These results therefore suggest that genetic alterations involving critical tumor suppressor genes such as $R b$ and $A P C$ genes take place in early lesions, with the exception of intestinal metaplasia.

We were able to document in three patients the presence of clonal molecular alterations in a number of tissue samples (from squamous epithelium to columnar metaplasia). In particular, we observed (a) p53 mutation in squamous epithelium and in nonintestinal metaplasia, (b) D5S82 allelic imbalance in squamous 
epithelium and D5S82 LOH in nonintestinal metaplasia, and (c) D17S513 allelic instability in squamous epithelium and intestinal metaplasia with low-grade dysplasia, D17S513 LOH in squamous epithelium, and nonintestinal metaplasia. These data are in agreement with other groups' results regarding clonal genetic alterations (van Dekken et al, 1999) in Barrett's epithelium, pointing out that new and advanced methods (Whittles et al, 1999) may help in evaluating the cancerogenic potential of Barrett's metaplasia and that of squamous tissue next to metaplastic and/or dysplastic epithelium (Barrett et al, 1999; Dolan et al, 2000).

Our results could have significant clinical implications, in particular for a more appropriate, individualized follow-up of patients with proven clonal abnormalities in their Barrett's mucosa. To this end, prospective studies will be required to confirm the presence of microsatellite molecular alterations in the different type of metaplastic tissues and their possible tumorigenic potential. The results of our investigation suggest that every kind of Barrett's metaplasia may harbor molecular alterations, and this raises the issue of whether Barrett's mucosa with dysplastic changes should be routinely evaluated for $p 53$ mutation and/or $17 \mathrm{p} \mathrm{LOH}$, because these might be reliable molecular markers of the evolution towards cancer. Further studies should also determine whether these alterations could be demonstrated in serial biopsies of the same patient and whether they might be reversed by early successful treatment of the esophageal reflux.

In conclusion, molecular alterations have been documented in endoscopic biopsies of Barrett's mucosa, unassociated with traditional morphologic features of increased risk for cancer such as intestinal metaplasia and glandular dysplasia. These are equally represented in all types of metaplastic mucosa and even in histologically normal squamous epithelium. The prevalence of the described molecular alterations is consistent with the model of esophageal cancerogenesis recently proposed by Montesano et al (1996). According to this model, p53 mutation provides the critical step toward dysplastic and neoplastic transformation. As our results suggest, this seems to be one of the most important events also in metaplastic columnar changes.

\section{Materials and Methods}

Forty-one cases of Barrett's esophagus, diagnosed from 1993 to 1998, were retrieved from the files of the Department of Pathology of the Milan University School of Medicine at San Paolo Hospital and Humanitas Clinical Institute. Case selection required foci of metaplasia suitable for microdissection and the presence of fragments of normal esophageal and/or gastric mucosa for $\mathrm{LOH}$ studies.

Routine hematoxylin and eosin-stained slides were evaluated for the presence of Barrett's esophagus and columnar epithelial dysplasia. Barrett's metaplasia was classified as either fundic type, cardial type, or columnar type with and without intestinal metaplasia.
Combined metaplasia, comprising two or more of these types, was also classified.

Three hematoxylin and eosin stained sections (8 $\mu$ thick) were microdissected using an Eppendorf (Hamburg, Germany) micromanipulator 5171. Each type of metaplastic change detectable in individual cases was subject to microdissection so that a mean of three to four microdissected samples were obtained, including the nearby adjacent squamous epithelium. Areas enriched for each type of metaplasia were collected in Eppendorf tubes, lyophilized, and resuspended in digestion mixture (50mM Tris- $\mathrm{HCl}, \mathrm{pH} 8 ; 5 \mathrm{mM}$ EDTA; $0.5 \%$ Tween 20; $400 \mathrm{ng} / \mu \mathrm{l}$ Proteinase K). Samples were digested overnight at $55^{\circ} \mathrm{C}$. Proteinase $\mathrm{K}$ was inhibited by boiling for 7 minutes. Digested samples were stored at $4^{\circ} \mathrm{C}$.

$\mathrm{LOH}$ of the short arm of chromosome 17 (17p13.1) was assessed by microsatellite assay using polymerase chain reaction (PCR) amplification of marker D17S513; LOH of the long arm of chromosome 5 (5q21) by a microsatellite marker inside the APC gene, D5S82 (Peng et al, 1995); and LOH on chromosome $13 q 14$ by a microsatellite marker, CA repeat inside $R b$ gene, intron 2, position 14815 to 14998 (Ashida et al, 1997). PCR-based microsatellite fluorescent assays were performed for 40 cycles $\left(94^{\circ} \mathrm{C}\right.$ for 1 minute, $55^{\circ} \mathrm{C}$ for 1 minute, and $72^{\circ} \mathrm{C}$ for $1 \mathrm{~min}$ ) in a $25 \mu \mathrm{l}$ volume with 10 pmoles of each primer.

The polymerase chain reaction products were analyzed by ABI Prism 310 (PE Biosystems, Foster City, California), and results were evaluated with the support of GeneScan software (Applied Biosystems, Foster City, California). Only informative cases (heterozygous for the microsatellite markers used) were considered for analysis. PCR amplification and analysis were confirmed twice for each microsatellite marker.

Allelic loss of a polymorphic marker was considered to be present according to the criteria of Canzian et al (1996). Allelic instability of a microsatellite was defined as the presence of at least one additional band in the DNA from Barrett's mucosa that was not present in the control sample. Allelic imbalance was defined by the decrease of one allele in proportion to the other, as evaluated using GeneScan software.

p53 gene mutations were assessed by SSCP, as previously described (Bosari et al, 1995), and mutations were characterized by DNA cycle sequencing, using Big Dye terminator chemistry on an ABI 310 automated sequencer (Applied Biosystems).

\section{References}

Ashida K, Kishimoto Y, Nakamoto K, Wada K, Shiota G, Hirooka Y, Kamisaki Y, Itoh T, and Kawasaki H (1997). Loss of heterozygosity of the retinoblastoma gene in liver cirrhosis accompanying hepatocellular carcinoma. J Cancer Res Clin Oncol 123:489-495.

Barrett MT, Galipeau PC, Sanchez CA, Emond MJ, and Reid BJ (1996). Determination of the frequency of loss of heterozygosity in esophageal adenocarcinoma by cell sorting, whole 
genomic amplification and microsatellite polymorphisms. Oncogene 12:1873-1878.

Barrett MT, Sanchez CA, Prevo LJ, Wong DJ, Galipeau PC, Paulson TG, Rabinovitch PS, and Reid BJ (1999). Evolution of neoplastic cell lineages in Barrett oesophagus. Nat Genet 22:106-109.

Blount PL, Galipeau PC, Sanchez CA, Neshat K, Levine DS, Yin J, Suzuki H, Abraham JM, Meltzer SJ, and Reid BJ (1994). 17p allelic losses in diploid cells of patients with Barrett's esophagus who develop aneuploidy. Cancer Res 54:2292-2295.

Blount PL, Meltzer SJ, Yin J, Huang Y, Krasna MJ, and Reid BJ (1993). Clonal ordering of the $17 p$ and $5 q$ allelic losses in Barrett's dysplasia and adenocarcinoma. Proc Natl Acad Sci USA 90:3221-3225.

Bosari S, Marchetti A, Buttitta F, Graziani D, Borsani G, Loda M, Bevilacqua G, and Coggi G (1995). Detection of p53 mutations by single-strand conformation polymorphisms (SSCP) gel electrophoresis. A comparative study of radioactive and nonradioactive silver-stained SSCP analysis. Diagn Mol Pathol 4:249-255.

Boynton RF, Huang Y, Blount PL, Reid BJ, Raskind WH, Haggitt RC, Newkirk C, Resau JH, Yin J, McDaniel T, and Meltzer SJ (1991). Frequent loss of heterozygosity at the retinoblastoma locus in human esophageal cancers. Cancer Res 51:5766-5769.

Campomenosi P, Conio M, Bogliolo M, Urbini S, Assereto P, Aprile A, Monti P, Aste H, Lapertosa G, Inga A, Abbondandolo A, and Fronza $G$ (1996). p53 is frequently mutated in Barrett's metaplasia of the intestinal type. Cancer Epidemiol Biomarkers Prev 5:559-565.

Canzian F, Salovaara R, Hemminki A, Kristo P, Chadwick RB, Aaltonen LA, and de la Chapelle A (1996). Semiautomated assessment of loss of heterozygosity and replication error in tumors. Cancer Res 56:3331-3337.

Casson AG, Mukhopadhyay T, Cleary KR, Ro JY, Levin B, and Roth JA (1991). p53 gene mutations in Barrett's epithelium and esophageal cancer. Cancer Res 51:4495-4499.

Dolan K, Garde J, Walker SJ, Sutton R, Gosney J, and Field JK (1999). LOH at the sites of the DCC, APC, and TP53 tumor suppressor genes occurs in Barrett's metaplasia and dysplasia adjacent to adenocarcinoma of the esophagus. Hum Pathol 30:1508-1514.

Dolan K, Garde J, Walker SJ, Sutton R, Gosney J, and Field JK (2000). Histological and molecular mapping of adenocarcinoma of the oesophagus and gastroesophageal junction: Loss of heterozygosity occurs in histologically normal epithelium in the oesophagus and stomach. Oncol Rep 7:521-528.

Galipeau PC, Prevo LJ, Sanchez CA, Longton GM, and Reid BJ (1999). Clonal expansion and loss of heterozygosity at the chromosomes $9 p$ and $17 p$ in premalignant esophageal (Barrett's) tissue. J Natl Cancer Inst 91:2087-2095.

Gleeson CM, Sloan JM, McGuigan JA, Ritchie AJ, and Russell SE (1995). Base transitions at CpG dinucleotides in the p53 gene are common in esophageal adenocarcinoma. Cancer Res 55:3406-3411.

Goldman H, Hayek J, and Federman M (1996). Inflammatory disorders of the esophagus. In: Gastrointestinal mucosal biopsy. New York: Churchill Livingstone Inc., 11-49.

Gonzalez MV, Artimez ML, Rodrigo L, Lopez-Larrea C, Menendez MJ, Alvarez V, Perez R, Fresno MF, Perez MJ,
Sampedro A, and Coto E (1997). Mutation analysis of the p53, APC and p16 genes in the Barrett's esophagus, dysplasia and adenocarcinoma. J Clin Pathol 50:212-217.

Hamelin R, Flejou JF, Muzeau F, Potet F, Laurent-Puig P, Fekete F, and Thomas G (1994). TP53 gene mutations and p53 protein immunoreactivity in malignant and premalignant Barrett's esophagus. Gastroenterology 107:1012-1018.

Hammoud ZT, Kaleem Z, Cooper JD, Sundaresan RS, Patterson GA, and Goodfellow PJ (1996). Allelotype analysis of esophageal adenocarcinomas: Evidence for the involvement of sequence on the long arm of chromosome 4. Cancer Res 56:4499-4502.

Huang Y, Boynton RF, Blount PL, Silverstein RJ, Yin J, Tong Y, McDaniel TK, Newkirk C, Resau JH, Sridhara R, Reid BJ, and Meltzer SJ (1992). Loss of heterozygosity involves multiple tumor suppressor genes in human esophageal cancers. Cancer Res 52:6525-6530.

Jankowski JA, Wright NA, Meltzer SJ, Triadafilopoulos G, Geboes K, Casson AG, Kerr D, and Young LS (1999). Molecular evolution of the metaplasia-dysplasiaadenocarcinoma sequence in the esophagus. Am J Patho 154:965-973.

Meltzer SJ (1996). The molecular biology of esophageal carcinoma. Recent Results Cancer Res 142:1-8.

Meltzer SJ, Yin J, Huang Y, McDaniel TK, Newkirk C, Iseri O, Vogelstein B, and Resau JH (1991). Reduction to homozygosity involving $p 53$ in esophageal cancers demonstrated by the polymerase chain reaction. Proc Natl Acad Sci USA 88:4976-4980.

Meltzer SJ, Yin J, Manin B, Rhyu MG, Cottrell J, Hudson E, Redd JL, Krasna MJ, Abraham JM, and Reid BJ (1994). Microsatellite instability occurs frequently and in both diploid and aneuploid cell populations of Barrett's associated esophageal adenocarcinomas. Cancer Res 54:3379-3382.

Montesano R, Hollstein M, and Hainaut P (1996). Genetic alterations in esophageal cancer and their relevance to etiology and pathogenesis: A review. Int J Cancer 69:225235.

Neshat K, Sanchez CA, Galipeau PC, Blount PL, Levine DS, Joslyn G, and Reid BJ (1994). p53 mutations in Barrett's adenocarcinoma and high-grade dysplasia. Gastroenterology 106:1589-1595.

Peng HQ, Bailey D, Bronson D, Goss PE, and Hogg D (1995). Loss of heterozygosity of tumor suppressor genes in testis cancer. Cancer Res 55:2871-2875.

Roncalli M, Bosari S, Marchetti A, Buttitta F, Bossi P, Graziani D, Peracchia A, Bonavina L, Viale G, and Coggi G (1998). Cell cycle-related gene abnormalities and product expression in esophageal carcinoma. Lab Invest 78:1049-1057.

Schneider PM, Casson AG, Levin B, Garewal HS, Hoelscher AH, Becker K, Dittler HJ, Cleary KR, Troster M, Siewert JR, and Roth JA (1996). Mutations of p53 in Barrett's esophagus and Barrett's cancer: A prospective study of ninety-eight cases. J Thorac Cardiovasc Surg 111:323-333.

Souza RF and Meltzer SJ (1997). The molecular basis for carcinogenesis in metaplastic columnar-lined esophagus. Gastroenterol Clin North Am 26:583-597.

van Dekken H, Vissers CJ, Tilanus HW, Tanke HJ, and Rosenberg C (1999). Clonal analysis of a case of multifocal oesophageal (Barrett's) adenocarcinoma by comparative genomic hybridization. J Pathol 188:263-266. 
Walch AK, Zitzelsberger HF, Bruch J, Keller G, Angermeier D, Aubele MM, Mueller J, Stein H, Braselmann H, Siewert JR, Hofler H, and Werner M (2000). Chromosomal imbalances in Barrett's adenocarcinoma and the metaplasia-dysplasiacarcinoma sequence. Am J Pathol 156:555-566.

Whittles CE, Biddlestone LR, Burton A, Barr $H$, Jankowski JA, Warner PJ, and Shepherd NA (1999). Apoptotic and proliferative activity in the neoplastic progression of Barrett's oesophagus: A comparative study. J Pathol 187:535-540.

Wu TT, Watanabe T, Heitmiller R, Zahurak M, Forastiere AA, and Hamilton SR (1998). Genetic alterations in Barrett esophagus and adenocarcinomas of the esophagus and esophagogastric junction region. Am J Pathol 153:287-294.
Ying H, Boynton F, Blount PL, Silverstein RJ, Yin J, Tong Y, McDaniel TK, Newkirk C, Resau JH, Sridhara R, Reid BJ, and Meltzer SJ (1992). Loss of heterozygosity involves multiple tumor suppressor genes in human esophageal cancers. Cancer Res 52:6525-6530.

Zhuang Z, Vortmeyer AO, Mark EJ, Odze R, Emmert-Buck MR, Merino MJ, Moon H, Liotta LA, and Duray PH (1996). Barrett's esophagus: Metaplastic cells with loss of heterozygosity at the APC gene locus are clonal precursors to invasive adenocarcinoma. Cancer Res 56:1961-1964. 